\title{
Antioxidant effect of aqueous extract of four plants with therapeutic potential on gynecological diseases; Semen persicae, Leonurus cardiaca, Hedyotis diffusa, and Curcuma zedoaria
}

Shaojian Ji, Amir Fattahi, Nathalie Raffel, Inge Hoffmann, Matthias W. Beckmann, Ralf Dittrich* and Michael Schrauder

\begin{abstract}
Background: Little information is available concerning antioxidant effects of plant teas (water boiled) which are used more commonly in traditional Chinese medicine than other extracts. Thus, we addressed this issue by evaluating the ability of teas from four different plants with therapeutic potential on gynecological diseases.

Methods: The aqueous extracts of Semen persicae, Leonurus cardiaca, Hedyotis diffusa, and Curcuma zedoaria rhizome were prepared and then their effects on copper-induced low-density lipoprotein cholesterol (LDL-C) oxidation were evaluated by spectrophotometric method. Density gradient ultracentrifugation method was recruited to isolate LDL-C from healthy individuals.
\end{abstract}

Results: Our results showed that adding 10,20, and $30 \mu \mathrm{l}$ S. persicae could increase the lag phase duration of LDL-C oxidation compared with control reaction 12,21 , and $33 \%$, respectively. The most effective delay (87\%) was observed when $30 \mu \mathrm{H} \mathrm{H}$. diffusa was added to the reaction. In cases of L. cardiaca and C. zedoaria, we found no significant influence on the lag phase duration ( $p>0.05$ ). Moreover, our findings about starting point of the decomposition phase were almost in parallel with the lag phase results, as $30 \mu \mathrm{l}$ of S. persicae or $\mathrm{H}$. diffusa teas could significantly increase the initiation time of decomposition $(p<0.05)$.

Conclusions: In conclusion our results showed that both S. persicae and H. diffusa teas and not L. cardiaca and C. zedoaria could have medicinal therapeutic effects partly through direct oxidation prevention.

Keywords: Antioxidants, Curcuma zedoaria, Herbal medicine, Hedyotis diffusa, Leonurus cardiac, Semen persicae

\section{Background}

Oxidative stress, an imbalance between formation and elimination of reactive oxygen species (ROS), is one of the major causes of many diseases including cancer [1], diabetes mellitus [2], atherosclerosis [3], and more importantly gynecological diseases especially endometriosis [4], polycystic ovarian syndrome (PCOS) [5], and

*Correspondence: ralf.dittrich@uk-erlangen.de

OB/GYN, University Hospital Erlangen, Friedrich-Alexander University, Universitätsstrasse 21-23, Erlangen-Nürnberg, 91054 Erlangen, Germany menstruation disturbances [6,7]. Such negative effects of excessive ROS are due to oxidative damage of various cellular components including lipids, proteins, and nucleic acids [8]. Previous studies have mentioned the beneficial and preventive effects of antioxidant substances on oxidative stress-induced diseases via scavenging free radicals $[9,10]$. In this concept, therapeutic effects of various antioxidants on female reproductive system diseases such as dysmenorrhea [11, 12], PCOS [13], and endometriosis [14] have been documented. Although, artificial antioxidants are extensively used in 
food products and medications but due to their instability and also possible potential in acting as carcinogens, there is a growing interest towards using natural antioxidants $[15,16]$. In this case, herbal medicinal plants which are well-known in folk medicine and contain potent antioxidant substances such as phenolic acid, flavonoids, and tannins have attracted a considerable attention $[17,18]$. Thus, numerous studies have been conducted to investigate therapeutic and preventive roles of various herbal extracts in gynecological diseases. For example, in a study conducted by Yang et al. [19] beneficial influence of Panax Ginseng Meyer on gynecologic complaints including menstrual irregularity and pain through improving oxidative status has been indicated. However, little information is available concerning antioxidant capacity of some herbal plants of which aqueous extractions are used as teas in traditional Chinese medicine; their medicinal potential in female health has been emphasized.

The Semen persicae, also called Taoren (or peach kernel), consists of the substantial part of the harvested peaches which is mostly considered as waste and lowvalue residue [20]. However, the S. persicae is considered as one of the important herbal products in traditional Chinese medicines [21]. Its beneficial effects on various pathological situations has been indicated including diverse womb as well as abdominal disorders and most commonly blood stasis [22]. Besides, its lipid and Malondialdehyde (MDA) lowering properties have been documented [23]. Moreover, based on the ancient literature this plant could regulate menstruation and relieve pain (reviewed in Ref. [21]). However, based on our knowledge its possible antioxidant potency especially as aqueous extract has not been investigated yet.

Leonurus cardiaca also commonly called motherwort can be found widely throughout Europe and Asia [24]. The $L$. cardiaca has a 100-year history of use for the treatment of nervous and functional cardiac disorders in Europe [25]. Moreover, for many years, traditional Chinese medicines have applied this plant to treat different disorders such as blood stasis, irregular menstrual cycle, urine excretion problems, and inflammatory diseases [26]. Besides, traditional application of this plant in menopause and menstrual disorders (dysmenorrhea or absent menstruation) has been reported [27, 28]. Further researches also confirmed its antinociceptive, hypoglycemic, anticancer, antibacterial, antifungal, and antioxidant properties $[29,30]$. However, the antioxidant capacity of its tea has not been sufficiently addressed yet.

Hedyotis diffusa Willd (Oldenlandia diffusa, Rubiaceae) is an ancient Chinese herbal which can be found in Asian countries including China; its aqueous extract (boiled in water) is employed to treat many kinds of diseases [31]. Applying of the $H$. diffusa for treatment of diverse types of inflammation and cancer have been reported previously [32]. Besides, investigations have shown antifungal, anti-inflammatory, immunoregulatory, and antioxidant attributes of this plant [33] that make this plant a potential therapeutic herbal for female-specific disorders; however, based on our knowledge there is no study about therapeutic application of $H$. diffusa in female reproductive system diseases. Huan-huan et al. [34] demonstrated that alcohol-ethyl acetate extract of this plant has radical scavenging activity and could protect DNA from hydroxyl radical-induced damages. However, antioxidant potency of the $H$. diffusa tea is still unknown.

Curcuma zedoaria (Rosc. Zingiberaceae), a plant found in tropical countries, is widely used in the traditional Chinese medicine, especially its tea that is made from dried rhizomes [35]. This plant is clinically applied in treatment of cancers, stomach diseases, chronic pelvic inflammation, blood stagnation, coronary heart disease, and anemia [36]. Powder of the dried plant is also applied for treatment of menstrual irregularities [37]. Previous studies have confirmed its antimicrobial, anti-inflammatory, and analgesic activities [38]. More interestingly, there are evidences about effective antioxidant capacity of the C. zedoaria rhizomes essential oil as well as aqueous and methanolic extracts [38, 39].

Considering pivotal roles of oxidative stress in various disorders such as gynecological diseases there is wide interest to use herbal medicinal plants which contain antioxidant substances to prevent such oxidation. On the other hand, most studies have paid attention on oils or other extracts of the plants and little information is available concerning antioxidant effect of the plant teas (water boiled) which are used more commonly than other extracts. Thus, we addressed this issue by evaluating the ability of teas from four different plants to prevent copper-catalyzed low-density lipoprotein cholesterol (LDL-C) oxidation; in particular, we investigated antioxidant activity of four plants with therapeutic potential on gynecological diseases, S. persicae, L. cardiaca, H. diffusa, and C. zedoaria tea.

\section{Methods \\ LDL-C fraction isolation, purification, and measurement}

Fasting blood samples were collected from healthy volunteers into EDTA-containing tubes and subsequent plasma separation was performed by centrifugation. LDL-C isolation was carried out immediately using density gradient ultracentrifugation. We applied the Abbey et al. [40] protocol briefly as follows: Firstly, using $\mathrm{KBr}$, the plasma density was adjusted to $1.21 \mathrm{~g} / \mathrm{ml}$ and then the plasma was layered under $\mathrm{NaCl}$ solution $(d=1.006 \mathrm{~g} / \mathrm{ml})$ containing $0.1 \%$ EDTA in Quickseal tubes. After preparation of the tubes, they were centrifuged at $4{ }^{\circ} \mathrm{C}$ and $280,000 \times g$ for 
$6 \mathrm{~h}$ by sequential ultracentrifugation (Beckman Ultracentrifuge, type L5-75, Ti 75 rotor). Afterwards, the LDL-C band (yellow band) was collected.

In order to purify the LDL-C particles we applied the gel filtration method. Briefly, the gel bed column was washed twice with PBS buffer and then $800 \mu$ of isolated LDL-C were added to the column; afterwards, the LDL-C was eluted from the column by adding $2.6 \mathrm{ml}$ PBS buffer. To confirm purity of isolated fractions, agar-agarose gel electrophoresis was employed; the results showed that the LDL-C content was more than $96 \%$ in all eluates.

LDL-C cholesterol levels were also evaluated in each eluate based on an enzymatic colorimetric method using automatic analyzer (Olympus AU 2700, NY, USA).

\section{Preparation of the teas}

Dried forms of $S$. persicae, $L$. cardiaca, $H$. diffusa, as well as $C$. zedoaria rhizome were purchased from a traditional Chinese pharmacy (Wenzhou, China). Considering that these herbal plants commonly are used as tea through boiling in water, we also prepared the teas with this method. For this purpose, $20 \mathrm{~g}$ of each dried plants were added into $100 \mathrm{ml}$ distilled water and the water was heated for 20 to $30 \mathrm{~min}$ until it started to boil. After $20 \mathrm{~min}$ of boiling, the aqueous extracts were filtered to avoid any solid particles; we let the teas cool down to room temperature and used them freshly for antioxidant evaluation.

\section{Evaluation of LDL-c oxidation delay}

The copper-induced LDL-C oxidation is accompanied by an increase in levels of dienes which have a maximum absorbance at $234 \mathrm{~nm}$. The LDL-C oxidation consists of three phases including lag, propagation, and decomposition phase [41]. The lag phase is an oxidation-resistant step in which diene levels and consequently absorbance at $234 \mathrm{~nm}$ is almost constant. However, upon the propagation phase, the absorbance quickly increases and finally reaches the maximum level.

In the present study we evaluated direct effects of different tea concentrations on preventing LDL-C oxidation and delaying the lag phase duration. For this purpose, 10,20 , and $30 \mu \mathrm{l}$ of each tea were added into a $0.08 \mathrm{mg}$ LDL-C-containing eluate and the final reaction volume was adjusted to $1 \mathrm{ml}$ using $\mathrm{O}_{2}$-saturated PBS buffer. Adding $\mathrm{CuSO}_{4}$ to the reaction and mixing the reaction batch initiated the oxidation process; absorbance at $234 \mathrm{~nm}$ was continuously measured at $30{ }^{\circ} \mathrm{C}$ for maximum $2 \mathrm{~h}$ (depending on the lag phase duration). Two reactions without tea (control) and two additional reactions for all three tea concentrations $(10,20$, and $30 \mu \mathrm{l})$ were carried out for each tea simultaneously. Besides, all reactions were conducted three times. The intercept of the baseline and slope of the absorbance curve in the propagation phase was defined as the lag phase; the data were expressed in minutes. The peak time was considered as the time of maximum absorbance (Fig. 1).

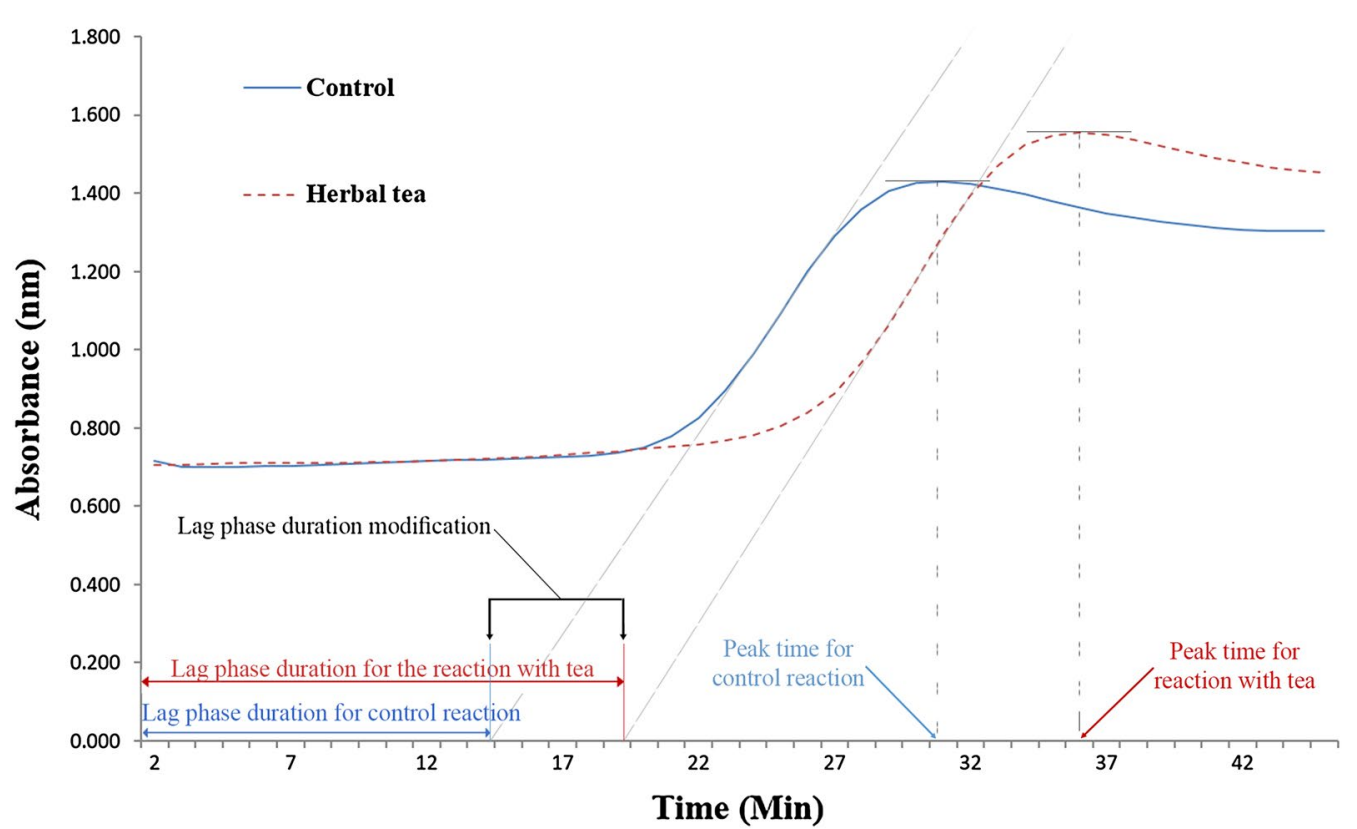

Fig. 1 An example for kinetics of LDL oxidation in control and herbal tea added reactions 


\section{Statistical analysis}

Kolmogorov-Smirnov test was used to confirm the normal distribution of data. One-Way ANOVA test following Tukey's post hoc test was applied to compare the data among groups. All Statistical analyses were conducted using SPSS (version 16). Differences between means were considered significant when $p$ value was 0.05 or less.

\section{Results}

The effects of $S$. persicae, $L$. cardiaca, $H$. diffusa, and $C$. zedoaria teas with various doses $(0,10,20$, and $30 \mu \mathrm{l})$ on duration of LDL-C oxidation lag phase are shown in Table 1 . Our results showed that adding $30 \mu \mathrm{l}$. persicae tea to the LDL-C oxidation reaction could significantly delay the lag phase in comparison to the control reaction without tea $(p=0.018)$. The lag phase durations in lower doses of $S$. persicae tea $(10$ and $20 \mu \mathrm{l})$ were also higher than the control (without tea); nevertheless, this difference did not reach statistical significance $(p>0.05)$. In case of $H$. diffusa tea, we also observed a dose-dependent correlation between tea amount and lag phase duration.
As adding $20 \mu \mathrm{l}$ of the tea to the reaction could cause $29.63 \pm 2.12 \mathrm{~min}$ lag phase which was significantly higher than lag phase duration in reactions without or with $10 \mu \mathrm{l}$ of the tea ( $p=0.001$ and 0.023 , respectively). Moreover, we found that the lag phase duration in reactions with $30 \mu \mathrm{l} H$. diffusa tea was statistically significant longer than the reactions without or with 10 and $20 \mu$ of the same tea ( $p<0.001, p<0.002$ and $p=0.032$, respectively).

In order to provide better understanding about effects of the teas on LDL-C oxidation we calculated the lag phase modification of each tea in comparison to corresponding reactions without the tea and illustrated the results as percentage in Fig. 2. We found that higher amounts of the teas $(30 \mu \mathrm{l})$ could have a higher effect on duration of the lag phase as adding 10,20 , and $30 \mu \mathrm{l}$ $S$. persicae could increase the phase duration compared with control reaction, respectively, 12,21 , and $33 \%$. The most effective delay was observed when $30 \mu \mathrm{H}$. diffusa was added to the reaction; it caused about $87 \%$ increase in the lag phase duration. Adding 10 and $20 \mu \mathrm{l}$ of $H$. diffusa caused a lag phase extension of 22 and 55\%,

Table 1 Effect of four herbal teas on the lag phase duration (min) of copper-induced low-density lipoprotein cholesterol oxidation

\begin{tabular}{|c|c|c|c|c|}
\hline & \multicolumn{4}{|c|}{ Tea concentrations } \\
\hline & 0 (control) & $10 \mu \mathrm{l}$ & $20 \mu \mathrm{l}$ & $30 \mu \mathrm{l}$ \\
\hline Semen persicae & $23.75 \pm 2.18$ & $26.55 \pm 1.83$ & $28.60 \pm 5.04$ & $31.37 \pm 1.70^{\mathrm{a}}$ \\
\hline Leonurus cardiaca & $23.20 \pm 2.54$ & $25.10 \pm 3.67$ & $26.70 \pm 3.95$ & $27.30 \pm 5.23$ \\
\hline Hedyotis diffusa & $19.06 \pm 0.11$ & $23.16 \pm 1.04$ & $29.63 \pm 2.12^{a, b}$ & $35.70 \pm 3.48^{a, b, c}$ \\
\hline Curcuma zedoaria & $19.75 \pm 3.60$ & $22.30 \pm 2.12$ & $24.80 \pm 3.95$ & $25.70 \pm 0.28$ \\
\hline
\end{tabular}

Significant difference $(p<0.05)$ in comparison with ${ }^{\mathrm{a} C}$ Control, ${ }^{\mathrm{b}} 10 \mu \mathrm{l}$ and ${ }^{\mathrm{c}} 20 \mu \mathrm{l}$ tea concentrations

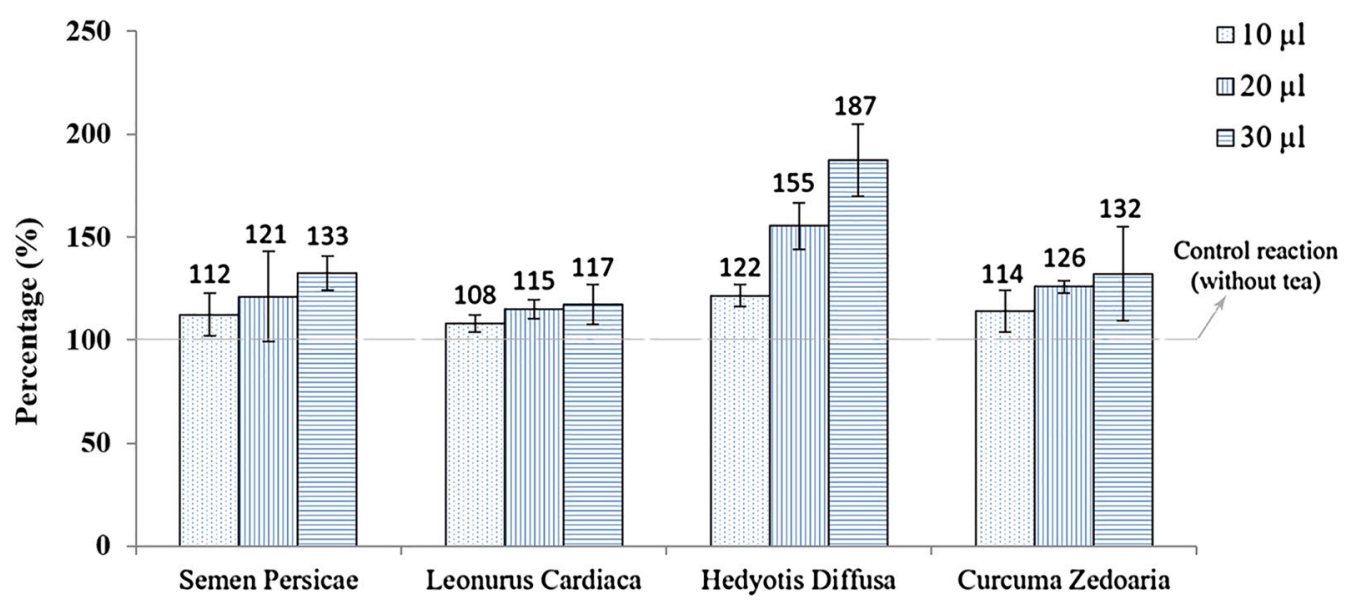

Herbal teas

Fig. 2 Percentage of the lag phase duration modification in low-density lipoprotein cholesterol oxidation following addition of four teas. All three different quantities per tea are depicted and the control reaction is set as $100 \%$ 
respectively. We further evaluated peak time in all reactions; peak time shows the starting point of the decomposition phase in LDL-C oxidation (Table 2). The obtained results were almost in parallel with our findings about lag phase, as addition of $30 \mu \mathrm{l}$ S. persicae and $H$. diffusa tea could significantly increase the peak time compared to reactions without and with $10 \mu \mathrm{l}$ of the teas. (for S. persicae $p=0.001$ and 0.016 and for $H$. diffusa $p=0.003$ and 0.009 , respectively).

\section{Discussion}

Considering existence of wide interest among people to use various medicinal plants as teas and also due to lack of information about antioxidant effects of such teas, we investigated antioxidant potency of $S$. persicae, $L$. cardi$a c a, H$. diffusa, and C. zedoaria teas in preventing LDL-C oxidation in the present study.

In case of $S$. persicae, we found that adding $30 \mu \mathrm{l}$ of the tea to LDL-C oxidation reaction could prolong the lag phase and prevent oxidation of LDL-C. An ancillary increase in peak time of LDL-C oxidation following the tea adding demonstrated the potential of this tea in even decreasing oxidation rate; however, lack of significant effects with lower amounts $(10$ and $20 \mu \mathrm{l})$ revealed that the antioxidant capacity is not that much potent in these cases. Previous studies on S. persicae, have mostly focused on its anti-coagulatory and anti-inflammatory effects; although the latter effect could also be partly a result of its antioxidant activity [42]. However, in accordance with our findings, Wu et al. [43] have reported the ability of $S$. persicae meal in scavenging radicals, notwithstanding they used various chemical solutions such as petroleum ether to extract the meal. Moreover, in an in vivo study, it has been demonstrated that oral administration of S. persicae decoction in hyperlipidemia patients could decrease plasma levels of MDA which is a lipid peroxidation marker [44]. Considering the ability of the

\section{Table 2 Comparison of the peak time (min) of copper- induced low-density lipoprotein cholesterol oxidation among reactions with four herbal teas}

\begin{tabular}{|c|c|c|c|c|}
\hline & \multicolumn{4}{|c|}{ Tea concentrations } \\
\hline & 0 (control) & $10 \mu \mathrm{l}$ & $20 \mu \mathrm{l}$ & $30 \mu \mathrm{l}$ \\
\hline $\begin{array}{l}\text { Semen } \\
\text { persicae }\end{array}$ & $33.75 \pm 2.21$ & $37.75 \pm 2.36$ & $41.50 \pm 5.68$ & $47.75 \pm 4.27^{a, b}$ \\
\hline $\begin{array}{l}\text { Leonurus } \\
\text { cardiaca }\end{array}$ & $34.0 \pm 1.41$ & $36.50 \pm 3.53$ & $38.00 \pm 4.24$ & $40.00 \pm 8.48$ \\
\hline $\begin{array}{l}\text { Hedyotis } \\
\text { diffusa }\end{array}$ & $33.33 \pm 0.57$ & $36.66 \pm 0.57$ & $44.00 \pm 4.00$ & $53.00 \pm 8.00^{a, b}$ \\
\hline $\begin{array}{l}\text { Curcuma } \\
\text { zedoaria }\end{array}$ & $33.00 \pm 4.24$ & $35.50 \pm 3.53$ & $38.50 \pm 4.94$ & $41.00 \pm 2.83$ \\
\hline
\end{tabular}

Significant difference $(p<0.05)$ in comparison with ${ }^{\mathrm{a}}$ Control and ${ }^{\mathrm{b}} 10 \mu \mathrm{l}$ tea concentration tea in delaying LDL-C lag phase as well as slowing oxidation propagation phase, it could be postulated that the antioxidant activity of $S$. persicae tea includes chelation of copper ions, neutralizing free radicals, and decomposing ox-LDL-C. Such antioxidant activities could be obtained from phenolic compounds of the tea [45]. Although we did not evaluate phenolic composition of the tea; nevertheless, previous studies showed the existence of high amounts of phenolic compounds in S. persicae meals extracted by Soxhlet extractor [43]. So most likely the tea also has such components and could play a role as an antioxidant solution. Higher antioxidant activity of $30 \mu \mathrm{l}$ tea in comparison to lower amounts in preventing LDL-C oxidation is logical as the higher tea amount would have higher quantities of phenolic compounds and an increased antioxidant activity; this is in agreement with previously reported findings $[43,46]$. So it could be postulated that therapeutic effect of $S$. persicae on endometriosis [47], removing blood stasis [22], and menstrual irregularity [21] could be partly through its antioxidant properties, as an association between oxidative stress and these disorders has been previously reported $[4,6,7]$.

$H$. diffusa, like S. persicae, showed antioxidant activity even in lower amounts. We found that adding $30 \mu \mathrm{l}$ of the $H$. diffusa tea to the LDL-C oxidation reaction could prolong the lag phase about $87 \%$ and also could significantly increase the peak time. Such a strong inhibitory effect of this tea in inhibiting LDL-C oxidation could introduce the $H$. diffusa tea as a potential drink to prevent oxidative stress-related gynecological diseases such as PCOS and endometriosis. However, further in vivo studies on patients with oxidative stress-related diseases are required to clarify the tea beneficial influences. Although the water extract of this plant has not been evaluated in terms of antioxidant activity and just its anticancer properties have been indicated [31], Bhuyan et al. [48] have reported radical scavenging capacity of the plant ethanol extract; this is in confirmation of our study. Besides, Huan-huan and colleagues [34] have documented that alcohol-ethyl acetate extract of $H$. diffusa has the ability to chelate ferrous iron, so one of the possible mechanisms of the tea in preventing copper-induced LDL-C oxidation might be chelating copper ions. Another possible reason for inhibitory effects of $H$. diffusa on LDL-C oxidation could be the presence of phenolic compounds such as phenolic acids and flavonols, as reported previously [49]. Moreover, in a study conducted by Yan et al. [50], four polysaccharides with strong hydroxyl radical scavenging activity in water/alkaline extraction and ethanol precipitation of $H$. diffusa have been detected. Yan et al. also claimed that higher doses from two of the polysaccharides have a more significant radical scavenging activity than vitamin $\mathrm{C}$ at the same dose. The presence of 
such polysaccharides in the tea could also be considered as a reason for its antioxidant capacity.

Interestingly, we found no statistically significant effect of L. cardiaca tea on LDL-C oxidation. Contrary to our findings, antioxidant activity of L. cardiaca alcoholic extract has been reported in both in vitro and in vivo conditions [51, 52]. Lack of significant effects of $L$. cardiaca tea on LDL-C oxidation in our study could be considered from different points of view. First, it is possible that reported beneficial influences of $L$. cardiaca on oxidative stress and lipid peroxidation are results of indirect effects of the plant rather than the direct mechanism. Supporting this idea, it has been mentioned that the antioxidant effects of $L$. cardiaca are only present in oxidative stress conditions and most probably through increasing antioxidant enzyme activities such as superoxide dismutase (SOD) and glutathione peroxidase (GPx) [53]. However, reports about in vitro antioxidant activity of the plant extract implies potential of a direct radical scavenging ability [30]. Second explanation for our contrary results could be absence or low concentration of antioxidant compounds in L. cardiaca plant; however, reports about presence of antioxidant compounds such as flavonoids, triterpenoids, and alkaloids in the plant extracts rejects such a hypothesis [54]. Another possible reason could be inadequacy of water as a solvent for preparing $L$. cardiaca extract with antioxidant capacity. In support of this reason, it has been reported that the water extract of $L$. cardiaca fruits had lower antioxidant activity compared with ethyl acetate, propyl alcohol, and supercritical $\mathrm{CO}_{2}$ extracts [55]. Thus, adding higher amounts of water-boiled extract (tea) might have caused a statistically significant effect on LDL-C oxidation. However, it should be mentioned that our aim was to evaluate antioxidant capacity of herbal medicine prepared using traditional Chinese medicine method rather than lipophilic extraction methods. Another possible reason could be inadequacy of water as a solvent for preparing $L$. cardiaca extract with antioxidant capacity. In support of this reason, it has been reported that the water extract of $L$. cardiaca fruits had lower antioxidant activity compared with ethyl acetate, propyl alcohol, and supercritical $\mathrm{CO}_{2}$ extracts [55]. Thus, adding higher amounts of water-boiled extract (tea) might have caused a statistically significant effect on LDL oxidation. A further potential reason for lack of antioxidant capacity in this plant could be due to the thermal condition in the tea preparation. However, this possibility seems unlikely because the plant was boiling for up to $20 \mathrm{~min}$ and the time duration is not comparable with the studies that have reported adverse effects of heating [56]. On the other hand, some studies even reported beneficial effect of such a short heating for increasing antioxidant activity of the herbal extracts [57, 58].

Like L. cardiaca tea, the tea prepared from C. zedoaria also did not have a significant influence on LDL-C oxidation which is in contradiction with previous findings. Previous studies have indicated antioxidant activity of C. zedoaria essential oil [38]. Also it has been reported that $C$. zedoaria extracts, prepared using methanol, chloroform, hexane, and ethyl acetate, could have various antioxidant activities such as scavenging and chelating abilities [39, 59]. The abovementioned reasons for $L$. cardiaca could also be considered as explanations for contradictory results in case of $L$. cardiaca tea.

\section{Conclusions}

In conclusion, our results show that both S. persicae and $H$. diffusa teas could prevent and also decrease the rate of LDL-C oxidation. However, statistically significant effects were not found for the L. cardiaca and C. zedoaria teas, possibly due to an inefficient extracting method and/or low antioxidant capacity of the plants. Considering the high prevalence of consuming medicinal plants as teas and on the other hand necessity of evaluating potential antioxidant capacity as well as side effects of such teas, future studies should shed more light on these issues; including beneficial effects in oxidative stress-related gynecological diseases.

\section{Abbreviations \\ MDA: malondialdehyde; PCOS: polycystic ovarian syndrome; ROS: reactive oxy- gen species; SOD: superoxide dismutase; GPx: glutathione peroxidase.}

\section{Authors' contributions \\ SJ: laboratory analysis and experimental works and acquisition of data. AF: statistical analysis and manuscript drafting. NR, LL, IH: laboratory analysis and experimental works. MB: manuscript critical revision. RD: study design, interpretation of data, and revision of the manuscript. MS: manuscript criti- cal revision and statistical analysis. All authors read and approved the final manuscript.}

\section{Acknowledgements}

The research for this study was performed by Shaojian Ji in fulfillment of the requirements for the M.D. degree at Friedrich-Alexander University, ErlangenNürnberg, Germany.

Competing interests

The authors declare that they have no competing interests.

Availability of data and materials

Data and material are available upon request.

Consent for publication

Not applicable.

Ethics approval and consent to participate Not applicable.

Funding

No specific funding was received for the study. This study was financially supported by institutional funding.

\section{Publisher's Note}

Springer Nature remains neutral with regard to jurisdictional claims in published maps and institutional affiliations. 
Received: 5 September 2017 Accepted: 15 November 2017

Published online: 25 November 2017

\section{References}

1. Gill JG, Piskounova E, Morrison SJ. Cancer, oxidative stress, and metastasis. In: Cold Spring Harb Symp Quant Biol. Cold Spring Harbor: Cold Spring Harbor Laboratory Press; 2016.

2. Asmat U, Abad K, Ismail K. Diabetes mellitus and oxidative stress-a concise review. Saudi Pharm J. 2016;24:547-53.

3. Förstermann $\mathrm{U}, \mathrm{Xia} \mathrm{N}$, Li H. Roles of vascular oxidative stress and nitric oxide in the pathogenesis of atherosclerosis. Circ Res. 2017;120:713-35.

4. Donnez J, Binda MM, Donnez O, Dolmans M-M. Oxidative stress in the pelvic cavity and its role in the pathogenesis of endometriosis. Fertil Steril. 2016;106:1011-7.

5. Yeon Lee J, Baw C-K, Gupta S, Aziz N, Agarwal A. Role of oxidative stress in polycystic ovary syndrome. Curr Women's Health Rev. 2010;6:96-107.

6. Dudas I, Rockenbauer M, Czeizel A. The effect of preconceptional multivitamin supplementation on the menstrual cycle. Arch Gynecol Obstet. 1995;256:115-23

7. Incebiyik A, Camuzcuoglu A, Hilali NG, Ulas T, Vural M, Camuzcuoglu H, Aksoy N. Serum oxidative stress, visfatin and apelin in healthy women and those with premenstrual syndrome. J Obstet Gynaecol. 2015;35:188-92.

8. Sies H. Oxidative stress. London: Academic Press Inc.; 2013.

9. Tousoulis D, Psaltopoulou T, Androulakis E, Papageorgiou N, Papaioannou S, Oikonomou E, Synetos A, Stefanadis C. Oxidative stress and early atherosclerosis: novel antioxidant treatment. Cardiovasc Drugs Ther. 2015:29:75-88.

10. Goodarzi MT, Khodadadi I, Tavilani H, Abbasi Oshaghi E. The role of Anethum graveolens L.(Dill) in the management of diabetes. J Trop Med. 2016:2016:1-11.

11. Rasgon NL, Yargin KN. Vitamin E for the treatment of dysmenorrhea. BJOG. 2005:112:1164.

12. Kashanian M, Lakeh MM, Ghasemi A, Noori S. Evaluation of the effect of vitamin $E$ on pelvic pain reduction in women suffering from primary dysmenorrhea. J Reprod Med. 2013;58:34-8.

13. Banaszewska B, Wrotynska-Barczynska J, Spaczynski RZ, Pawelczyk L Duleba AJ. Effects of resveratrol on polycystic ovary syndrome: a doubleblind, randomized placebo-controlled trial. J Clin Endocrinol Metab. 2016:101:4322-8.

14. Mier-Cabrera J, Aburto-Soto T, Burrola-Méndez S, Jiménez-Zamudio L, Tolentino MC, Casanueva E, Hernández-Guerrero C. Women with endometriosis improved their peripheral antioxidant markers after the application of a high antioxidant diet. Reprod Biol Endocrinol. 2009;7:54

15. Pokorný J. Natural antioxidants for food use. Trends Food Sci Technol. 1991:2:223-7.

16. Abbasi Oshaghi E, Goodarzi MT, Higgins V, Adeli K. Role of resveratrol in the management of insulin resistance and related conditions: mechanism of action. Crit Rev Clin Lab Sci. 2017:54:267-93.

17. Wong C-C, Li H-B, Cheng K-W, Chen F. A systematic survey of antioxidant activity of 30 Chinese medicinal plants using the ferric reducing antioxidant power assay. Food Chem. 2006;97:705-11.

18. Oshaghi EA, Khodadadi I, Tavilani H, Goodarzi MT. Aqueous extract of Anethum Graveolens L. has potential antioxidant and antiglycation effects. Iran J of Med Sci. 2016;41:328-33.

19. Yang $M$, Lee $H-S$, Hwang M-W, Jin M. Effects of Korean red ginseng (Panax Ginseng Meyer) on bisphenol. A exposure and gynecologic complaints: single blind, randomized clinical trial of efficacy and safety. BMC Complement Altern Med. 2014;14:265.

20. Pelentir N, Block J, Monteiro Fritz AR, Reginatto V, Amante ER. Production and chemical characterization of peach (Prunus persica) kernel flour. J Food Process Eng. 2011:34:1253-65.

21. Xi S, Qian L, Tong H, Yue L, Zhao H, Wang D, Lu D, Li P, Wang X. Toxicity and clinical reasonable application of Taoren (Semen Persicae) based on ancient and modern literature research. J Tradit Chin Med. 2013;33:272-9.

22. Kuang $L$, Zhang K, Commission CP. Pharmacopoeia of the People's Republic of China 2005. Beijing: People's Medical Publishing House; 2005.
23. Chen X, Zhang Q, Yang Q, Xie Q, Shen Q, Xu Y. Effects of Tao Ren Hong Hua Jian on hyperlipidemia without symptoms. Chin J Pathophysiol. 2002;18:1529-31.

24. Wu C, Li H. Labiatae. In: 'Flora Reipublicae Popularis Sinicae, vol 65 (Ed. E Committee). Beijing: Science Press; 1977. p. 505-21.

25. Miłkowska-Leyck K, Filipek B, Strzelecka H. Pharmacological effects of lavandulifolioside from Leonurus cardiaca. J Ethnopharmacol. 2002:80:85-90

26. Commission CP. Chinese pharmacopoeia. Beijing: China Medical Science Press; 2010. p. 228.

27. Rotblatt M. Herbal medicine: expanded commission E monographs. Ann Intern Med. 2000;133:487.

28. Yingqun $X$. Clinical observation of motherwort capsules for treatment of primary dysmenorrhea. J New Chin Med. 2014;12:055.

29. Ojewole J. Antinociceptive, antiinflammatory and antidiabetic effects of Leonotis leonurus (L.) R. BR. (Lamiaceae) leaf aqueous extract in mice and rats. Methods Find Exp Clin Pharmacol. 2005;27:257-64.

30. Tahmouzi S, Ghodsi M. Optimum extraction of polysaccharides from motherwort leaf and its antioxidant and antimicrobial activities. Carbohydr Polym. 2014;112:396-403.

31. Gupta S, Zhang D, Yi J, Shao J. Anticancer activities of Oldenlandia diffusa. J Herb Pharmacother. 2004:4:21-33.

32. Ahmad R, Ali AM, Israf DA, Ismail NH, Shaari K, Lajis NH. Antioxidant, radical-scavenging, anti-inflammatory, cytotoxic and antibacterial activities of methanolic extracts of some Hedyotis species. Life Sci. 2005;76:1953-64.

33. Li H, Qing C, Zhang Y, Zhao Z. Screening for endophytic fungi with antitumour and antifungal activities from Chinese medicinal plants. World J Microbiol Biotechnol. 2005;21:1515-9.

34. Huan-Huan D, Shu-Wen C, Yan-Ying Y. Antioxidant and free radical scavenging activities of extracts from Scutellaria barbata D. Don, Hedyotis diffusa Willd and their combination. Nat Prod Res Dev. 2008:20:782-6.

35. Lakshmi S, Padmaja G. Remani P Antitumour effects of isocurcumenol isolated from Curcuma zedoaria rhizomes on human and murine cancer cells. Int J Med Chem. 2011. https://doi.org/10.1155/2011/253962.

36. OaA Hamdi, Ye LJ, Kamarudin MNA, Hazni H, Paydar M, Looi CY, Shilpi JA, Kadir HA, Awang K. Neuroprotective and antioxidant constituents from Curcuma zedoaria rhizomes. Rec Nat Prod. 2015;9:349.

37. Ullah HA, Zaman S, Juhara F, Akter L, Tareq SM, Masum EH, Bhattacharjee $R$. Evaluation of antinociceptive, in vivo \& in vitro anti-inflammatory activity of ethanolic extract of Curcuma zedoaria rhizome. BMC Complement Altern Med. 2014;14:346.

38. Mau J-L, Lai EY, Wang N-P, Chen C-C, Chang C-H, Chyau C-C. Composition and antioxidant activity of the essential oil from Curcuma zedoaria. Food Chem. 2003:82:583-91.

39. Huang SJ, Chyau CC, Tsai CH, Chen CC, Mau JL, Tsai SY. Antioxidant properties of extracts from Curcuma zedoaria rhizome. In: Advanced materials research. Zurich: Trans Tech Publications; 2015.

40. Abbey M, Nestel P, Baghurst PA. Antioxidant vitamins and low-densitylipoprotein oxidation. Am J Clin Nutr. 1993;58:525-32.

41. Esterbauer $\mathrm{H}$, Gebicki J, Puhl H, Jürgens $\mathrm{G}$. The role of lipid peroxidation and antioxidants in oxidative modification of LDL. Free Radical Biol Med. 1992;13:341-90.

42. Jin S-J, Zhang H-Y, Piao H-S, Li L. Effects of ethanol extract of the Semen persicae for bleeding time and coagulation time in mice. J Med Sci Yanbian Univ. 2010:2:010.

43. Wu H, Shi J, Xue S, Kakuda Y, Wang D, Jiang Y, Ye X, Li Y, Subramanian J. Essential oil extracted from peach (Prunus persica) kernel and its physicochemical and antioxidant properties. LWT Food Sci Technol. 2011;44:2032-9.

44. Chen X-Y, Zhang Q, Yang Q-H, Xie Q-L, Shen Q, Xu Y-S. Effects of Taoren Honghua Jian on the hyperlipidemia without symptom. Chin J Pathophysiol. 2002;18(12):1529-31.

45. Osawa T. Novel natural antioxidants for utilization in food and biological systems. In: Uritani I, Garcia W, Mendoza EM, editors. Postharvest biochemistry of plant food-materials in the tropics. Japan Scientific Societies Press; 1994. p. 241-51.

46. Ismail HI, Chan KW, Mariod AA, Ismail M. Phenolic content and antioxidant activity of cantaloupe (Cucumis melo) methanolic extracts. Food Chem. 2010;119:643-7. 
47. Wang D, Wang Z, Yu C. Endometriosis treated by the method of resolving blood stasis to eliminate obstruction in the lower-jiao. J tradit Chin Med (Chung i tsa chih ying wen pan). 1998;18:7-11.

48. Bhuyan DJ, Barooah MS. Evaluation of antifungal, antibacterial and antioxidant activities of amphineuron extensus, hedyotis diffusa and vitex negundo. J Cell Tissue Res. 2012;12:3343-48.

49. Cai Y, Luo Q, Sun M, Corke H. Antioxidant activity and phenolic compounds of 112 traditional Chinese medicinal plants associated with anticancer. Life Sci. 2004;74:2157-84.

50. Yan C, Kong F, Ou X. Antioxidant and anti-glycated activities of polysaccharides in vitro isolated from Hedyotis diffusa Willd. J Med Plants Res. 2012;6:2895-900.

51. Sun J, Huang SH, Zhu YC, Whiteman M, Wang MJ, Tan BK-H, Zhu YZ. Antioxidative stress effects of Herba leonuri on ischemic rat hearts. Life Sci. 2005;76:3043-56.

52. Liu X-H, Xin H, Zhu Y. More than a " mother-benefiting" herb: cardioprotective effect of Herba leonuri. Sheng li xue bao:(Acta physiologica Sinica). 2007;59:578-84

53. Loh KP, Qi J, Tan BKH, Liu XH, Wei BG, Zhu YZ. Leonurine protects middle cerebral artery occluded rats through antioxidant effect and regulation of mitochondrial function. Stroke. 2010;41:2661-8.
54. Ulubelen A, Topcu G, Kolak U. Labiatae flavonoids and their bioactivity. Stud Nat Prod Chem. 2005;30:233-302.

55. Ye S, Xin S, Gang L, Tan L. Antioxidant activity of fruits of Herba Leonuri. In: International conference on human health and biomedical engineering (HHBE). 2011. Jilin, China.

56. Cheng Z, Su L, Moore J, Zhou K, Luther M, Yin J-J, Yu L. Effects of postharvest treatment and heat stress on availability of wheat antioxidants. J Agric Food Chem. 2006;54:5623-9.

57. Jeong S-M, Kim S-Y, Kim D-R, Jo S-C, Nam K, Ahn D, Lee S-C. Effect of heat treatment on the antioxidant activity of extracts from citrus peels. J Agric Food Chem. 2004:52:3389-93.

58. Kim S-Y, Jeong S-M, Park W-P, Nam K, Ahn D, Lee S-C. Effect of heating conditions of grape seeds on the antioxidant activity of grape seed extracts. Food Chem. 2006;97:472-9.

59. Rahman A, Afroz M, Islam R, Islam KD, Hossain MA, Na M. In vitro antioxidant potential of the essential oil and leaf extracts of Curcuma zedoaria Rosc. J Appl Pharm Sci. 2014;4:107-11.

\section{Submit your next manuscript to BioMed Central and we will help you at every step:}

- We accept pre-submission inquiries

- Our selector tool helps you to find the most relevant journal

- We provide round the clock customer support

- Convenient online submission

- Thorough peer review

- Inclusion in PubMed and all major indexing services

- Maximum visibility for your research

Submit your manuscript at www.biomedcentral com/submit 